\title{
NAS ENTRELINHAS DO CORPO: \\ A elaboração da AIDS em À l'ami qui ne m’a pas sauvé la vie, de Hervé Guibert, e "Cartas para além do muro", de Caio Fernando Abreu Guilherme FERNANDES ${ }^{1}$
}

RESUMO: A partir de um estudo comparado dos textos À l'ami qui ne m'a pas sauvé la vie, de Hervé Guibert, e "Cartas para além do muro", de Caio Fernando Abreu, este artigo tem por objetivo analisar a maneira segundo a qual esses autores elaboraram, através de seus textos literários, a experiência do corpo que passaram a vivenciar quando da descoberta de que estavam com AIDS. Seus textos apontam para um movimento de elaboração estética do corpo, fazendo da escritura um instrumento fundamental para refletir sobre suas condições de soropositividade em um período (fim da década de 1980 e início da década de 1990) em que o conhecimento acerca da enfermidade era limitado, ao passo que o preconceito em torno das formas de contágio e da vida sexual dos portadores do vírus HIV era ainda mais notório do que atualmente. Dessa forma, a base teórica deste estudo será pautada por autores que abordarem questões referentes ao corpo, poder, linguagem e identidade, como Michel Foucault, Susan Sontag e Judith Butler.

PALAVRAS-CHAVE: Corpo, escritura, AIDS, identidade, literatura comparada.

\footnotetext{
${ }^{1}$ Mestrando no programa de Estudos linguísticos, Literários e Tradutológicos em Francês da Universidade de São Paulo. Bolsista Capes. E-mail: guilherme.fernandes@usp.br
} 


\section{DANS LES ENTRE-LIGNES DU CORPS: L'ÉLABORATION DU SIDA DANS À L'AMI QUI NE M'A PAS SAUVÉ LA VIE, D'HERVÉ GUIBERT, ET “CARTAS PARA ALÉM DO MURO”, DE CAIO FERNANDO ABREU}

RÉSUMÉ: À partir d'une étude comparée des textes À l'ami qui ne m'a pas sauvé la vie, d'Hervé Guibert, et "Cartas para além do muro", de Caio Fernando Abreu, cet article se propose d'analyser la manière dont les auteurs ont élaboré, à travers leurs textes, l'expérience du corps qu'ils ont vécu après avoir découvert qu'ils étaient affectés par le SIDA. Leurs textes montrent un mouvement d'élaboration esthétique du corps, en faisant de l'écriture un outil fondamental pour réfléchir à leur condition de séropositivité à une période (la fin des années 1980 et le début des années 1990) où la connaissance de la maladie était encore limitée, tandis que les préjugés sur la transmission de la maladie et la vie sexuelle des porteurs du virus VIH étaient plus marqués qu'à époque actuelle. Ainsi, l'approche théorique de cette étude sera orientée par des auteurs qui traitent de questions relatives au corps, au pouvoir, à la langue et à l'identité, comme Michel Foucault, Judith Butler et Susan Sontag.

MOTS-CLÉS: Corps, écriture, SIDA, identité, littérature comparée.

\section{O CORPO PERFORMÁTICO}

Antes de partir para as proposições de análise de À l'ami qui ne m'a pas sauvé la vie e "Cartas para além do muro", tecerei algumas considerações sobre a produção prévia dos autores, a fim de entender, em que medida, a introdução do tema da AIDS conduz a um novo desafio na abordagem do corpo e da sexualidade, os levando a retomar e reinventar algumas perspectivas adotadas anteriormente.

As literaturas de Hervé Guibert e Caio Fernando Abreu, cujas obras se estendem, em ambos os casos, das décadas de 1960 a 1990, foram em diversos momentos utilizadas como um espaço de reflexão sobre o corpo, no qual as categorias rígidas de definição de gênero e sexualidade, como masculino e feminino, homem e mulher, eram constantemente colocadas em questão. Retiradas do domínio da natureza humana e inseridas no plano da performance, tais categorias deixam de ser percebidas como fatores imutáveis e passam a ser manipuladas com maior fluidez por esses autores.

Esta reflexão sobre o corpo como um espaço que possibilite a inscrição de valores e significados diversos começou a ser desenvolvida pelas ciências humanas a partir do século XX, recebendo contribuições da psicanálise, da antropologia e de outras áreas do saber. Estudos etnográficos de autores como Marcel Mauss (2003) e Pierre Clastres (2012), por exemplo, relataram como as relações entre sexo e gênero podem variar segundo diferentes contextos sociais, em alguns casos assu- 
mindo feições muito distantes do binarismo ao qual estamos habituados nas sociedades ocidentais modernas.

Penso, no entanto, que foi somente entre as décadas de 1960 e 1970 que os estudos sobre corpo e sexualidade, agora amparados pela semiologia e a análise do discurso, promoveram um rompimento mais expressivo em relação às antigas teorias naturalistas herdadas do século XIX, as quais consideravam o corpo como um elemento inequívoco do ser humano, onde, com um árduo trabalho de análise, poderiam ser descobertas as mais obscuras instâncias da natureza humana. Segundo Michel Foucault (2010), é desse esforço constante de análise do corpo levado a cabo no século XIX que foram estabelecidas categorias científicas referentes a todo um contingente de indivíduos cujas expressões de gênero e sexualidade destoavam do paradigma heterossexual. Termos como "homossexualismo" e "inversão" começaram então a ser usados para definir esses seres em desajuste. De acordo com o filósofo:

Esta nova caça às sexualidades periféricas provoca a incorporação das perversões e nova especificação dos indivíduos. A sodomia - a dos antigos direitos civil ou canônico - era um tipo de ato interdito e o autor não passava de seu sujeito jurídico. O homossexual do século XIX torna-se uma personagem: um passado, uma história, uma infância, um caráter, uma forma de vida; também é morfologia, com uma anatomia indiscreta e, talvez, uma fisiologia misteriosa. Nada daquilo que ele é, no fim das contas, escapa à sua sexualidade. Ela está presente nele todo: subjacente a todas as suas condutas. (FOUCAULT, 2010: 50).

Foucault admite que foi no século XIX que as perversões sexuais passaram a ser largamente estudadas e classificadas pela ciência. Atos como a masturbação feminina, a homossexualidade e o incesto deixaram de ser apreendidos como veleidades proibidas pelo Estado ou pela Igreja para serem enquadradas em categorias biológicas. A perversão, outrora restrita ao domínio da moral e dos bons costumes, é agora transferida ao domínio da ciência. Contudo, ao usar o termo "personagem", Foucault subverte essa ordem positivista e insere o diálogo sobre o corpo e a sexualidade humanas em outra área, desta vez mais próxima ao que é proposto neste estudo: a linguagem, ou, mais precisamente, a ficção.

As categorias criadas para definir o corpo humano, desde as mais elementares, como "homem" e "mulher", às mais complexas, como "invertidos" e "ninfomaníacos", são, no viés foucaultiano, construções históricas, que por serem compulsivamente repetidas, recebem o estatuto de "naturais". Diferentemente do discurso científico, que entende o corpo como uma espécie de baú pleno de conteúdo, onde se deve vasculhar para descobrir e caracterizar cada elemento ali presente, o filó- 
sofo analisa o corpo humano como se se tratasse de um baú previamente vazio, cujos elementos são inseridos com o passar dos anos, podendo ser retirados a qualquer momento e substituídos por outros. Sujeito a alterações, o corpo passa a ser entendido - sobretudo pelas teorias sobre o gênero formuladas posteriormente, com especial atenção para a teoria queer - mais pelo seu dinamismo e sua possibilidade de transformação do que por categorias que insistem em imobilizá-lo. Judith Butler, por exemplo, formula sua hipótese acerca das identidades de gênero a partir do que ela chamará de performatividade. Dentro dessa concepção, todo ato, gesto, desejo ou expressão de gênero é compreendido como uma atuação destituída de qualquer relação causal com uma possível natureza sexual do indivíduo: "O fato de o corpo gênero ser marcado pelo performativo sugere que ele não tem status ontológico separado dos vários atos que constituem sua realidade" (BUTLER, 2010: 194). As marcas de divisão de gênero, que incluem fatores como gestos corporais, comportamento e vestimenta, são formas de atuar no mundo. O corpo humano é o palco no qual mobilizamos essas características e construímos diferentes identidades. Ainda segundo Butler, as tentativas de reduzir esses atos a um núcleo interno e imutável do ser humano não passam de uma "ilusão mantida discursivamente com o propósito de regular a sexualidade nos termos da estrutura obrigatória da heterossexualidade reprodutora" (BULTLER, 2010: 195). Sendo assim, a teórica insere o debate sobre o corpo e o gênero no âmbito político, mostrando que, por trás dos discursos que defendem a ideia de que as expressões corporais estão submissas a fatores nucleares da natureza humana (incluindo o discurso científico e sua aparente imparcialidade), há um jogo de poder que visa reiterar e legitimar um sistema de convívio pautado por um padrão heterossexista, estabelecendo como norma a formação de famílias, o casamento e o sexo reprodutivo.

É nesse sentido que retomo os autores em questão neste estudo. Hervé Guibert e Caio Fernando Abreu elaboraram personagens que estão à margem desse sistema normativo. Corpos ambíguos, cujas expressões de gênero e sexualidade estão em constante transformação. De acordo com Roland Barthes:

A ciência é grosseira, a vida é sútil, e é para corrigir essa distância que a literatura nos importa. Por outro lado, o saber que ela mobiliza nunca é inteiro ou derradeiro; a literatura não diz que sabe alguma coisa, mas que sabe de alguma coisa; ou melhor; que ela sabe algo das coisas - que sabe muito sobre os homens. O que ela conhece dos homens é o que se poderia chamar de grande estrago da linguagem, que eles trabalham e que os trabalha, quer ela reproduza a diversidade dos socioletos, quer, a partir dessa diversidade, cujo dilaceramento ela ressente, imagine e busque elaborar uma linguagem-limite, que seria seu grau zero. Porque ela encena a linguagem, em vez de simplesmente utilizá-la, a li- 
teratura engrena o saber no rolamento da reflexibilidade infinita: através da escritura, o saber reflete incessantemente sobre o saber, segundo um discurso que não é mais epistemológico, mas dramático. (BARTHES, 2013: 19-20).

A longa citação de Barthes, extraída de sua Aula inaugural no Collège de France, contrasta o discurso científico ao discurso literário, acentuando neste último um caráter de reflexão constante. A literatura, diferentemente da ciência, é um espaço onde os saberes estão em movimento, não se encerram em termos e conceitos inequívocos e imutáveis. Dessa forma, no que diz respeito à abordagem do corpo e da sexualidade, a produção literária de Caio Fernando Abreu e Hervé Guibert se aproximam. Os saberes que definem e, por vezes, subjugam o corpo humano em categorias rígidas são inseridos neste espaço de "reflexibilidade infinita" da escritura, são dramatizados. Não é à toa que tanto Abreu quanto Guibert produziram obras que transitam entre diferentes gêneros e formas de expressão, situadas na fronteira entre o conto e o romance, a poesia e a prosa, a escritura e a imagem visual, a ficção e a autobiografia, são formas que, assim como a construção que esses autores fazem sobre o corpo humano, não assumem características fixas, mas transitórias: formas travestidas.

O escritor brasileiro, por exemplo, publicou em 1989 um volume com 13 narrativas intitulado Os dragões não conhecem o paraíso, o qual ele definiu, em nota introdutória, como sendo um romance-móbile: "Um romance desmontável”, diz ele, "onde essas 13 peças possam completar-se, esclarecer-se, ampliar-se ou remeter-se de muitas maneiras umas às outras, para formarem uma espécie de todo. Aparentemente fragmentado, mas de algum modo - suponho - completo" (ABREU, 2010: 7).

Essa interface entre as narrativas do livro ocorre de diferentes formas. As personagens, que em cada conto apresentam idades, estilos de vida e sexualidades diferentes, têm origem comum: uma cidade fictícia denominada Passo do Guanxuma, onde elas viveram suas infâncias. São muitas as passagens em que há menção a essa cidade, mas as memórias relacionadas a ela são sempre negativas e aparecem no presente da enunciação na forma de traumas. O que torna esse lugar tão ruim para as personagens do livro é justamente a política de controle do corpo e da sexualidade ali estabelecida. Trata-se de uma cidade interiorana conservadora, onde qualquer manifestação sexual ou expressão de gênero que desviasse da norma era rapidamente tornada pública e vista com maus olhos pelos demais habitantes.

Nesse sentido, o que une os diversos narradores-protagonistas do livro é também o desvio que eles apresentam diante da norma heterossexista de Passo do Guanxuma: são homossexuais, travestis, mulheres poligâmicas etc. Cada um, à sua maneira, assumiu para si identidades de gênero e comportamentos sexuais que desviam do que era considerado saudável em sua cidade natal. Ao fazerem isso, eles abrem espaço para novas formas de atuação no mundo, novas perfor- 
mances de gênero. O corpo, outrora restrito à "heterossexualidade reprodutora" para usar as palavras de Butler - se revela em múltiplas formas.

O último conto do livro, "Os dragões não conhecem o paraíso", o qual, aliás, dá nome ao volume, apresenta uma metáfora capaz de englobar todas essas personagens "desajustadas". Nele, o narrador descreve o comportamento de um dragão, metáfora que se refere a todo ser que destoa da norma:

Tudo o que faz, e que pode parecer perigoso, excêntrico ou no mínimo mal-educado para um humano igual a mim, é apenas parte dessa estranha natureza dos dragões (...). Cinzas são como seda para um dragão, nunca para um humano, porque a nós lembram destruição e morte, não prazer. Eles trafegam impunes, delicados, no limiar entre esta zona culta e a mais mundana. O que não podemos compreender, ou pelo menos aceitar (ABREU, 2010: 183).

A imagem do dragão como um ser limítrofe, que trafega por espaços perigosos, flertando com o que há de mais "perigoso, excêntrico ou no mínimo mal-educado" e buscando nisso uma fonte de prazer sinaliza a condição de muitas personagens dessa e de outras obras de Caio Fernando Abreu. Do começo ao fim do conto, a identidade do dragão é construída em contraste com a de um "ser humano comum", uma imagem que a tal ponto escapa à "normalidade" que o narrador só pode percebê-la e descrevê-la através de frases negativas: o dragão não é um humano comum, tudo o que ele faz está em desacordo com os padrões de higiene e sanidade e, mais importante, suas fontes de prazer são abjetas. No entanto, a presença desse corpo estranho e indefinível faz falta ao narrador-personagem:

No turvo seco de uma casa esvaziada da presença de um dragão, mesmo voltando a comer e a dormir normalmente, como fazem as pessoas banais, você não sabe mais se não seria preferível aquele pantanal de antes, cheio de possibilidades - que não aconteciam, mas que importa? - a esta secura de agora. Quando tudo, sem ele, é nada (ABREU, 2010: 189).

Apesar da repulsa com a qual o dragão é descrito, o seu comportamento excêntrico apresenta ao narrador um novo quadro de possibilidades. Trata-se de um corpo que foge ao cotidiano banal e estende sua busca por prazer, denunciando o que há de limitado na vida de um sujeito comum.

Na literatura de Hervé Guibert o corpo também é explorado segundo um potencial performático que escapa às normas. Em 1977 ele publica La mort propagande, um texto em primeira pessoa cujo principal personagem é o próprio corpo do narrador: 
Meu corpo é um laboratório que ofereço em exibição, o único ator, o único instrumento de meus delírios orgânicos. Partituras sobre tecidos de carne, de loucura, de dor. Observar como ele funciona, recolher suas prestações. Meus diferentes métodos de masturbação se enunciam. A realização se desenrola no caos próprio ao prazer ou à repulsa (é um texto anárquico) (GUIBERT, 2009: 8) ${ }^{23}$.

As diversas reações exibidas nesse "laboratório" não são, no entanto, separadas em categorias dicotômicas, uma vez que dor e deleite se misturam e, tal qual o dragão de Caio Fernando Abreu, este corpo busca suas fontes de prazer no que haveria de mais sujo e repulsivo, mesmo a morte é evocada segundo um critério positivo: "Ao final desta série de expressões, o último travestimento, a última maquiagem, a morte. Nós a amordaçamos, a censuramos, tentamos afogá-la em desinfetante, asfixiá-la no gelo. Eu quero deixá-la levantar sua voz poderosa e que ela cante, diva, através do meu corpo" (GUIBERT, 2009: 10) ${ }^{4}$.

Estes corpos que destoam da norma e se deleitam com o que comumente é tido como repulsivo e perigoso estão presentes em diversos momentos na literatura de Abreu e Guibert. A consciência do caráter performático por trás das expressões de gênero e sexualidade os conduz à elaboração de corpos/personagens que não se limitam a um padrão heteronormativo e que, apesar de se verem constantemente julgados, são capazes de expandir suas fontes de prazer. O corpo é explorado em todo seu potencial, extravasando o horizonte limitado de possibilidades ao qual se convencionou chamar de natural.

\section{O CORPO REDUZIDO}

O corpo performático, retratado como palco de inúmeras possibilidades de atuação, é um traço que se vê durante o percurso literário de Abreu e Guibert, contudo, as obras a serem analisadas neste estudo parecem seguir, senão um caminho inverso, ao menos mais delicado no que se refere à sexualidade. Isso se deve, evidentemente, às problemáticas em torno da AIDS. Se antes o corpo era apresentado em todo o seu potencial performático, buscando formas de atuar que escapavam às definições naturalistas, agora ele se vê inserido em um contexto que o limita de diversas maneiras: conduzido de um hospital a outro, submetido a uma

\footnotetext{
${ }^{2}$ As traduções dos trechos das obras em francês são de minha autoria.

3 "Mon corps est un laboratoire que j'offre en exhibition, l'unique acteur, l'unique instrument de mes délires organiques. Partitions sur tissus de chair, de folie, de douleur. Observer comme il fonctionne, recueillir ses prestations. Mes différentes méthodes de branlage s'énoncent. La réalisation se déroule dans le chaos propre au plaisir, ou à la revulsion (c'est un texte anarchique)".

${ }^{4}$ À l'issue de cette série d'expressions, l'ultime travestissement, l'ultime maquillage, la mort. On la bâillonne, on la censure, on tente de la noyer dans le désinfectant, de l'étouffer dans la glace. Moi je veux lui laisser élever sa voix puissante et qu'elle chante, diva, à travers mon corps".
} 
série de tratamentos com base em remédios e transfusões de sangue, inseguro quanto à possibilidade de se relacionar sexualmente, o que se observa em $\grave{A}$ l'ami qui ne m'a pas sauvé la vie e "Cartas para além do muro" é o retrato de um corpo reduzido, sem autonomia para atuar no mundo da maneira que lhe convém, frente à impossibilidade da performance: "Naquele dia poderiam me trepanar, plantar seringas na barriga e nos olhos, eu teria apenas apertado os dentes, havia lançado o meu corpo em alguma coisa que o despossuía, aparentemente, de uma vontade autônoma" (GUIBERT, 1990a: 211) ${ }^{5}$, diz o narrador de À l'ami qui ne m’a pas sauvé la vie, acentuando justamente a perda de controle dele em relação ao seu corpo.

Tanto Abreu quanto Guibert eram soropositivos, a experiência do corpo nestes textos tem a ver com a experiência que eles viveram em seus próprios corpos: as interferências médicas às quais eles foram submetidos, os preconceitos vividos, a relação conflituosa com amigos e família etc. Mesmo o título das "Cartas para além do muro" está relacionado com o fato de que Caio Fernando Abreu as escreveu dentro de um hospital, onde passava a maior parte de seu tempo, de modo que seus textos serviam como uma espécie de comunicação com o mundo externo, uma mensagem para além dos muros hospitalares.

Dentro desse quadro, é impossível dissociar completamente a voz dos narradores de À l'ami qui ne m'a pas sauvé la vie e "Cartas para além do muro" da voz de seus autores. Os textos são permeados de relatos autobiográficos envolvendo procedimentos médicos, viagens e visitas de amigos. No entanto, o que se verifica é que esses relatos, mais ou menos precisos, cedem rapidamente lugar a uma construção artística que excede o plano referencial. A escritura é o espaço a eles disponível para elaborar, dar forma ao que estavam vivendo em seus corpos, e dentro desta elaboração, obviamente, há muito de ficcional. Bruno Blanckeman utiliza a categoria de autoficção, cunhada por Serge Doubrovsky, para caracterizar a produção de Guibert. Segundo o crítico: "A autoficção representa (...) uma prática de escritura que intercala a relação fenomenológica bruta, que permite o estudo do corpo e da consciência, e o ato de fabulação, que se arrisca no imaginário e no inconsciente" (BLANCKEMAN, 2001: n. p.) ${ }^{6}$.

Não é à toa que Guibert classificou seu texto como um romance, pois apesar de se tratar de uma experiência pessoal, os fatos expostos no livro são dramatizados e muitas das situações apresentadas, conforme admitiu o autor, são inventadas:

Eu falo da verdade na medida em que ela pode vir a ser distorcida pelo trabalho da escritura. É por isso que eu me atenho à palavra romance. Meus modelos existem, mas são per-

\footnotetext{
${ }^{5} \mathrm{Ce}$ jour-là on aurait pu me trépaner, me planter des seringues dans le ventre et dans les yeux, j'aurais juste serré les dents, j'avais lancé mon corps dans quelque chose qui le dépossédait apparemment d'une volonté autonome".

${ }^{6}$ L'autofiction représente (...) une pratique d'écriture entremêlant la relation phénoménologique brute, qui permet l'étude du corps et de la conscience, et l'acte de fabulation, qui tente celle de l'imaginaire et de l'inconscient".
} 
sonagens. Eu me atenho à verdade na medida em que ela permite a adição de partículas de ficção, como colagens em películas, com a ideia de que seja o mais transparente possível. Mas há também grandes recursos à mentira neste livro [À l'ami qui ne m’a pas sauvé la vie] (GUIBERT, 199ob: n. p.)7.

As pessoas mencionadas no livro, como o doutor Chandi ou Muzil (pseudônimo que o autor escolheu para se referir a Michel Foucault) são, no espaço da escritura, convertidas em personagens. A realidade é considerada na medida em que os fatos vividos possam se converter em ficção, possam ser dramatizados. Nesse sentido, há um recorte no que deve ou não ser considerado na narrativa.

A própria relação de Abreu e Guibert com a doença é também dramatizada, a compreensão que eles têm da AIDS e do que ocorre em seus corpos se dá, sobretudo, por vias metafóricas. Já nas primeiras páginas de À l'ami qui ne m’a pas sauvé la vie o narrador deixa clara a sua recusa em descrever a doença através de termos meramente denotativos:

A AIDS não é realmente uma doença, dizer isso simplifica as coisas, trata-se de um estado de fraqueza e abandono que abre a jaula da besta que temos em nós, a quem eu sou obrigado a dar plenos poderes para que ela me devore, a quem eu deixo fazer com meu corpo vivo o que ela se prestaria a fazer com meu cadáver a fim de desintegrá-lo (GUIBERT,1990a: 17) ${ }^{8}$.

Abordar a AIDS e suas consequências no organismo a partir do conhecimento médico-científico seria simplificador, uma vez que, por mais minuciosa que fosse a descrição, não seria capaz de abranger o turbilhão de sensações e dúvidas que este novo estado imprimia no corpo: "Os pesquisadores não têm nenhuma ideia do que é a doença, eles trabalham com seus microscópios, com seus esquemas e abstrações, (...) eles nunca estão em contato com os doentes, não podem imaginar a dor deles, o sofrimento deles, o sentimento de urgência, eles não o têm" (GUIBERT, 1990a: 241)9.

\footnotetext{
${ }^{7}$ Je parle de la vérité dans ce qu'elle peut avoir de déformé par le travail de l'écriture. C'est pour cela que je tiens au mot roman. Mes modèles existent, mais ce sont des personnages. Je tiens à la vérité dans la mesure où elle permet de greffer des particules de fiction comme des collages de pellicule, avec l'idée que ce soit le plus transparent possible. Mais il y a aussi des grands ressorts de mensonge dans ce livre [A l'ami qui ne m'a pas sauvé la vie]".

8 "Le sida n'est pas vraiment une maladie, ça simplifie les choses de dire que c'en est une, c'est un état de faiblesse et d'abandon qui ouvre la cage de la bête qu'on avait en soi, à qui je suis contraint de donner pleins pouvoirs pour qu'elle me devore, à qui je laisse faire sur mon corps vivant ce qu'elle s'apprêtait à faire sur mon cadavre pour le désintégrer".

9 "Les chercheurs n'ont aucune idée de ce qu'est la maladie, ils travaillent sur leurs microscopes, sur des schémas, des abstractions (...) ils ne sont jamais en contact avec des malades, ils ne peuvent imaginer leur peur, leur souffrance, le sentiment de l'urgence ils ne l'ont pas".
} 
O narrador busca, nesse sentido, outros níveis de compreensão, e recorre, para tal, à metáfora da besta, um ser capaz de devorar ainda vivo o corpo do enfermo, sob o risco de desintegrá-lo paulatinamente, como um verme devorando um cadáver, o que ilustra o sentimento de urgência do indivíduo soropositivo, também enfatizado por Caio Fernando em suas "Cartas":

$\mathrm{Eu}$, porco sangrando em gritos desafinados, faca enfiada no ventre, entre convulsões e calafrios indignos. Eu gritava Senhor de Toda Luz de Tudo que Existe, dai-me Força, Fé e Luz. Gritei também não palavras, uivos, descobrindo na carne que o berro alivia a dor. Gado no matadouro, recém-nascido após o tapa e o choque, aterrorizado com a clareza dura e o ruído insuportável do mundo cá de fora. Grito também: Senhor, não agora, porque eu não quero que seja agora. Minhas histórias não escritas, meu jardim? (ABREU, 2006: 200).

Em uma espécie de delírio, no qual diversas imagens são usadas para tentar definir o estado de fragilidade do corpo, o narrador clama por mais tempo de vida. $\mathrm{O}$ sentimento de urgência é tamanho que a própria realização da escritura é ameaçada pelo estado de fraqueza do corpo. As "Cartas para além do muro" foram um conjunto de quatro textos publicados entre 1994 e 1995 na coluna que Caio Fernando Abreu mantinha no jornal O Estado de São Paulo, sendo que a última delas data de 24 de dezembro de 1995, apenas dois meses antes de sua morte, em 25 de fevereiro de 1996. Já o "romance" de Guibert foi publicado em 1990, um ano antes de seu falecimento. Esses textos fazem parte de uma época em que os tratamentos de combate à doença eram ineficazes comparados aos métodos antirretrovirais atuais. Uma vez manifesto, o vírus se desenvolvia rapidamente, alterando o organismo do paciente e reduzindo sua expectativa de vida a poucos anos: "O mais doloroso nas fases de consciência da doença mortal é, sem dúvida, a privação do distante, de todos os distantes possíveis" (GUIBERT, 1990a: 207) ${ }^{10}$. Diante da impossibilidade de traçar projetos em longo prazo, esses autores escreviam contra o tempo, enquanto observavam as alterações que o desenvolvimento da AIDS e os efeitos colaterais dos tratamentos produziam em seus organismos. Trata-se de uma experiência de escritura relacionada a uma experiência do corpo, como se pode notar na primeira carta escrita por Abreu:

É com terrível esforço que te escrevo. E isso agora não é mais apenas uma maneira literária de dizer que escrever significa mexer com funduras - como Clarice, feito Pessoa. Em Carson McCullers doía fisicamente, no corpo feito de

\footnotetext{
10 "Le plus douloureux dans les phases de conscience de la maladie mortelle est sans doute la privation du lointain, de tous les lointains possibles".
} 
carne e veias e músculos. Pois é no corpo que escrever me dói agora. Nestas duas mãos que você não vê sobre o teclado, com suas veias inchadas, feridas, cheias de fios e tubos plásticos ligados a agulhas enfiadas nas veias para dentro das quais escorrem líquidos que, dizem, vão me salvar (ABREU, 2006: 106).

O desenvolvimento da doença no corpo é, por vezes, acolhido com perplexidade por Guibert e Abreu. Fatores já mencionados, como a perda da autonomia e a impossibilidade de ação no mundo (de performance), distancia os autores da imagem que eles tinham de seus corpos (sua aparência, sua disposição para atividades físicas, suas manifestações sexuais etc.) num momento anterior à AIDS. Ao se olhar no espelho, Guibert afirma que não mais se reconhecia como um ser vivo: "este rosto emagrecido que o espelho toda vez reflete como algo que não pertence mais a mim, mas a meu cadáver" (GUIBERT, 1990a: 259) ${ }^{11}$. Diante desse estado de fragilização, a escritura é entendida pelos escritores como uma forma de resistência. Abreu segue o seu relato dizendo: "Dói muito, mas eu não vou parar. A minha não-desistência é o que de melhor posso oferecer a você [leitor] e a mim neste momento. Pois isso, saiba, isso que poderá me matar é a única coisa que poderá me salvar" (ABREU, 2006: 106). Escrever a dor, elaborar no corpo do texto a dor vivenciada no próprio corpo, esta é a melhor e talvez a única solução que eles encontraram para enfrentar a situação: "eu escolheria entre o suicídio e a escritura" (GUIBERT, 1990a: 60) ${ }^{12}$, diz o escritor francês em À l'ami qui ne m'a pas sauvé la vie.

Ambos os textos se apresentam como espaços de reflexão frente a uma situação de fragilidade, onde se observa uma relação íntima entre corpo e escritura. É importante ressaltar, no entanto, as diferenças que existem, sobretudo do ponto de vista da amplitude temporal, entre À l'ami qui ne m'a pas sauvé la vie e "Cartas para além do muro".

A obra de Guibert compreende um vasto espaço temporal, da década de 1970 até 1990. Durante esse tempo, muitos personagens aparecem no romance, amigos, médicos e familiares, mas dois deles assumem papéis centrais na condução da narrativa, a saber, Muzil, personagem baseado na amizade de Guibert com Michel Foucault, e Bill, um farmacêutico americano que trabalhava em um projeto de vacina para a AIDS, e que, ao longo da obra, vai assumindo um caráter antagônico, pois, apesar das inúmeras promessas que fizera, sua vacina nunca conseguiu sair do papel e gerou no narrador uma série de expectativas frustradas, de modo que o próprio título do livro, $\grave{A}$ l'ami qui ne m'a pas sauvé la vie, é uma dedicatória irônica associada a essa contenda entre Bill e Guibert.

\footnotetext{
11 "Ce visage décharné que le miroir chaque fois me renvoie comme ne m'appartenant plus mais déjà à mon cadavre".

12 "Je choisirais entre le suicide ou l'écriture".
} 
O texto é formulado a partir de uma mescla entre romance e diário. Muitos eventos distantes no tempo são reconstituídos e, durante esse processo, o uso do passé simple é predominante. Ocorre que o fio condutor da narrativa é interrompido diversas vezes, havendo saltos para momentos mais recentes de enunciação, marcados, desta vez, pelo uso do passé composé. Neles, o narrador se volta para sua própria experiência cotidiana de tratamento da doença, suas visitas ao hospital e as alterações que ele vê surgindo em seu corpo em decorrência da síndrome. Isso ocorre, pois, cada evento passado está associado ao presente. Em outras palavras, o passado é elaborado como um meio de compreensão do presente. Não é à toa que a primeira metade do livro, dedicada ao amigo Muzil, que morrera em decorrência da AIDS, preconiza diversos eventos pelos quais o próprio narrador viverá posteriormente, tendo ele também que lidar com a doença.

A construção do personagem inspirado em Michel Foucault merece especial atenção neste estudo por duas razões: a primeira delas está relacionada às reflexões propostas por ele durante a narrativa, as quais estão em confluência com o pensamento de Foucault em sua História da sexualidade. Já a segunda está relaciona às experiências do corpo vividas por Muzil, pois, como afirmei, elas serão "revividas" por Guibert. De acordo com Frédéric Gaussen, em artigo publicado no jornal Le Monde em 2000:

Guibert incarna o "dever de verdade" que Foucault persegue em sua História da sexualidade. E Guibert, sabendo que ele também vai morrer em decorrência da AIDS, conta a agonia de Foucault, seu declínio físico, seu sofrimento, mas também sua alegria estoica em face da morte. Assistindo à morte de Foucault, é sua própria morte que ele observa por antecipação (GAUSSEN, 200O: n. p. $)^{13}$.

A maneira com a qual Muzil lida com a doença é, de fato, marcada por uma indiferença estoica, até mesmo por certo humor sádico. Guibert observa admirado como seu amigo reagia às limitações físicas impostas pelo vírus. A preocupação do personagem recaía não nos efeitos da enfermidade no corpo físico, mas nos discursos que ela poderia acarretar. Desse modo, contrariamente a Guibert, que optou por se expor, Muzil prefere manter-se distante dos holofotes. Sendo ele uma pessoa conhecida pelo público, o personagem temia que sua condição de saúde também se tornasse de conhecimento geral: "Paris o impedia de sair, lá ele se sentia muito conhecido. Quando ia ao cinema todos os olhares convergiam sobre ele" (GUIBERT, 1990a: 29) ${ }^{14}$.

\footnotetext{
13 "Guibert incarne ce 'devoir de vérité' que poursuit Foucault à travers son Histoire de la sexualité. Et Guibert, qui sait que lui aussi va mourir du sida, raconte l'agonie de Foucault, sa déchéance physique à l'hôpital, sa souffrance mais aussi sa gaieté stoïcienne face à la mort. En regardant mourir Foucault, c'est sa propre mort qu'il observe par anticipation".

14 "Paris l'empêchait de sortir, il s'y sentait trop connu. Quand il allait au cinema, tous les regards convergeaient sur lui".
} 
Para Michel Foucault - desta vez falo do filósofo, não do personagem -, expor a sexualidade, seja em meios religiosos ou científicos, não era sinônimo de liberdade. Com o surgimento das nações modernas e das grandes metrópoles, o filósofo afirma que houve um esforço em tornar a sexualidade um problema de âmbito políticoadministrativo, cuja intenção era justamente de controlar as perversões, remediar qualquer conduta que desviasse da norma: "cumpre falar do sexo como de uma coisa que não se deve simplesmente condenar ou tolerar, mas gerir, inserir em sistemas de utilidades, regular para o bem de todos, fazer funcionar segundo um padrão ótimo. O sexo não se julga apenas, administra-se” (FOUCAULT, 2010: 30-31).

Por se tratar de uma doença cujo principal meio de contaminação ocorre por vias venéreas, o indivíduo soropositivo, ao expor sua condição, também abria espaço para que sua sexualidade viesse à tona e fosse alvo de análise. Para Susan Sontag, em AIDS e suas metáforas, num primeiro momento, muitos casos de HIV positivo foram detectados em homossexuais do sexo masculino, o que produziu todo um aparato discursivo associando a enfermidade à sexualidade desviante de indivíduos que não participavam de algumas convenções heteronormativas, como a monogamia, o casamento e a constituição de famílias: "O comportamento perigoso que produz a AIDS é encarado como algo mais do que fraqueza. É irresponsabilidade, delinquência - o doente é viciado em substâncias ilegais, ou sua sexualidade é considerada divergente" (SONTAG, 2007: 97). Para evitar esse tipo de análise sobre seu próprio corpo e sua identidade sexual, o personagem Muzil preferia encobrir sua condição de saúde. Em diversos momentos, é como se ele encarnasse, na narrativa, os pressupostos críticos de Foucault, em uma espécie de mise en abîme das teorias do filósofo francês.

Após a morte de Muzil, acompanhada de perto pelo narrador, a narrativa se centra cada vez mais no corpo de Guibert. Tudo o que fora relatado sobre o estado de saúde de Muzil é agora retomado sob a perspectiva própria do romancista, desde a descoberta do vírus até o desenvolvimento da AIDS e as limitações físicas causadas pela doença. Bill, o personagem que motivou o título do livro, também recebe mais espaço, uma vez que a urgência por um tratamento eficaz se acentua, e a espera pela vacina redentora se torna cada vez mais angustiante. Antes de, por ocasião de um jantar com amigos, o farmacêutico norte-americano falar sobre o desenvolvimento deste tratamento "definitivo" para a doença, Guibert dizia estar num estado de conformismo em relação à própria morte, e foi a notícia da vacina que lhe deu outra perspectiva: "Bill, que está em vias de me contradizer, senão de pôr em questão meu conformismo a uma morte muito próxima” (GUIBERT, 1990a: 185$)^{15}$. Se a vacina lhe deu esperança, também o fez entrar num estado de constante ansiedade: "Eu estava entrando em uma nova fase, de suspensões, de

\footnotetext{
15 "Bill, qui est en train de contredire, sinon de remettre en question mon accoutumance à une mort très proche".
} 
esperança e de incerteza, que era, talvez, mais atroz do que a precedente" (GUIBERT, 1990a: 188$)^{16}$.

É justamente quando Bill lhe anuncia a existência de uma vacina que o tempo do romance começa a ser marcado pelo próprio tempo do corpo, já que para ser funcional, o tratamento deveria ser iniciado antes que os níveis de T4, um hormônio responsável pela boa manutenção do sistema imunológico, estivessem inferiores a 200. Nesse momento, o índice de $\mathrm{T} 4$ passa a ser um marcador temporal na narrativa, conforme eles iam diminuindo, o corpo ficava mais fragilizado, e a possibilidade de ser curado seria extinta. Contudo, o tempo avança, a doença se agrava, e Bill se afasta da vida de Guibert, até o ponto de admitir que a vacina não resultaria em nada. A partir de então, a única salvação, o único modo de lidar com a doença era se dedicando à escrita, ainda que de forma obsessiva: "Tenho mais apreço ao meu livro do que à minha vida: eu não renunciaria ao meu livro para conservar minha vida, eis o que será mais difícil de fazer acreditar ou compreender" (GUIBERT, 1990a: 274) ${ }^{17}$. Ao final do romance, é como se o corpo tivesse chegado ao seu limite, e como corpo e escritura neste momento estão em simbiose, o livro se encerra no momento em que o narrador está mais debilitado fisicamente: "A mise en abîme do meu livro se encerra comigo. Eu estou na merda. Até onde desejas me ver caindo? Tome essa, Bill! Meus músculos derreteram. Enfim reencontrei minhas pernas e meus braços de criança” (GUIBERT, 1990a: 284) ${ }^{18}$.

As "Cartas para além do muro", de Caio Fernando Abreu, não assumem a forma e a abrangência de um romance tal qual se vê em Guibert. Desta vez, há a opção pelo gênero epistolar, pois como afirmado acima, elas fazem parte de uma tentativa de comunicação de Abreu com seu público leitor. Parte dessas cartas foram escritas durante sua estadia no hospital de infectologia Emílio Ribas, em São Paulo. Apesar de todas girarem em torno do tema da AIDS, elas se diferenciam em alguns aspectos. As duas primeiras, publicadas respectivamente em agosto de 1994 e setembro de 1994, agem como uma espécie de mensagem codificada. O autor fala dos tratamentos aos quais está sendo submetido, da experiência do corpo fragilizado, faz referência a outros artistas e intelectuais que enfrentaram a AIDS (mencionando, inclusive, Hervé Guibert), mas em nenhum momento cita o nome da doença, prefere chamá-la de "Coisa Estranha" ou "turvação":

Por enquanto ainda estou um pouco dentro daquela coisa estranha que me aconteceu. É tão impreciso chamá-la assim, a Coisa Estranha. Mas o que teria sido? Uma turvação, uma vertigem. Uma voragem, gosto dessa palavra que gira

\footnotetext{
16 "J'entrais dans une nouvelle phase, de suspensions, d'espoir et d'incertitude, qui était peutêtre plus atroce que la précédente".

17 "Je tiens à mon livre plus qu'à ma vie; je ne renoncerais pas à mon livre pour conserver ma vie, voilà ce qui sera le plus difficile à faire croire et comprendre".

18 "La mise en abîme de mon livre se referme sur moi. Je suis dans la merde. Jusqu'où souhaites-tu me voir sombrer? Pends-toi Bill! Mes muscles ont fondu. J'ai enfin retrouvé mes jambes et mes bras d'enfant".
} 
como um labirinto vivo, arrastando pensamento e ações nos seus círculos cada vez mais velozes, concêntricos, elípticos. Foi algo assim que aconteceu na minha mente, sem que eu tivesse controle algum sobre o final magnético dos círculos içando o início de outros para que tudo recomeçasse (ABREU, 2006: 106-107).

A "turvação" que a descoberta da Aids instaurou na mente do autor é expressa através de uma linguagem igualmente turva. As imagens se sucedem - "voragem", "labirinto vivo" - e a prosa assume um tom poético, acentuado pelo uso contínuo de sibilantes - "arrastando pensamento e ações nos seus círculos cada vez mais velozes, concêntricos, elípticos" -, o que reforça, no plano formal, a sensação vertiginosa provocada pelo diagnóstico.

Segundo Marcelo Secron Bessa: "Ter a AIDS como tema não implica que ela apareça explicitamente; através da elipse, o escritor pode criar, em relação à síndrome, novas formas de percepção ou outras abordagens" (BESSA, 1997: 51). Assim como Guibert, que se recusa a entender a AIDS meramente como uma doença, Abreu não se importa, neste primeiro momento, em descrever a síndrome em seus detalhes, até porque, mesmo nas áreas médicas, a AIDS ainda representava um grande desafio, não havia consenso quanto às formas de contaminação e ao desenvolvimento do vírus no corpo. Também segundo Bessa (1997: 78): "Esta sigla, assim diz o discurso científico, refere-se a uma síndrome que afeta o sistema imunológico. Os doentes, portanto, podem falecer devido a várias doenças em decorrência da AIDS, mas nunca de AIDS. Como, então, falar da 'AIDS em si'?”. Nesse sentido, Caio Fernando Abreu não utiliza suas cartas para refletir sobre o que é a AIDS, mas para refletir sobre seus efeitos no corpo e como essa crise no sistema imunológico o transforma.

É somente em sua terceira "Carta para além dos muros", também publicada em setembro de 1994, que o autor faz menção direta à síndrome. Nesse texto, ele abre mão de metáforas e opta por uma linguagem de cunho referencial: "Imagino que você tenha achado as duas cartas anteriores obscuras, enigmáticas como aquelas dos almanaques de antigamente. Gosto sempre do mistério, mas gosto mais da verdade. E por achar que esta lhe é superior te escrevo agora assim, mais claramente. Não vejo nenhuma razão para esconder. Nem sinto culpa, vergonha ou medo" (ABREU, 2006: 112).

$\mathrm{O}$ autor segue o relato dizendo quando fez o teste de HIV, salienta que o resultado foi positivo, em qual hospital foi internado, quando a doença se agravou, entre outros dados precisos sobre o tema, seguidos inclusive por suas datas. Ao contrário das duas primeiras, nada é metaforizado nesta epístola. Mesmo os efeitos da síndrome no corpo, antes apresentados por vias imagéticas, agora são descritos com base em um vocabulário médico-científico. Por não sentir "culpa, vergonha ou medo", o autor decide apresentar sua condição de saúde de maneira direta. 
Conforme salientado por Susan Sontag, admitir que estava com AIDS implicava em responder também por sua sexualidade, uma vez que a doença ficara conhecida na época como uma espécie de "peste gay". É importante para Caio Fernando Abreu superar este estigma, admitindo que estava contaminado pelo vírus e, sobretudo, enfatizando que não se sentia envergonhado por isso.

Por fim, a última carta escrita por Abreu é uma das mais dramáticas, pois nela o estado de saúde do autor já havia sido severamente afetado. Ele a escreve em dezembro de 1995, mais de um ano depois das outras três. Fica claro nesta epístola o quão incomodado o autor estava por saber que não lhe restava mais muito tempo de vida, sobretudo porque não haveria mais como se dedicar aos seus projetos literários:

Fico aflito, tenho sempre tanto medo que me desviem do que estou tentando desesperadamente organizar para dizer; qualquer atalho poderia me perder, e à minha quase história, para todo o sempre. E nada mais triste que histórias abortadas, arrastando correntes, fantasmas inconsoláveis (ABREU, 2006: 199).

Assim como Guibert, escrever se tornara vital para o autor brasileiro. Preservadas as diferenças entre À l'ami qui ne m'a pas sauvé la vie e as "Cartas para além do muro", esses textos oferecem um amplo horizonte de comparação, pois ambos se configuram como uma experiência de corpo e escritura. $\mathrm{O}$ ato de escrever é levantado por eles como a única maneira de lidar com as alterações que a síndrome causara em seus organismos. A elaboração artística desse estado de fragilização, ainda que demandasse desses escritores tempo e esforço, era uma forma de compreender o corpo e até mesmo de resgatá-lo, esquivando-se, assim, dos discursos preconceituosos que circulavam na época (inclusive aqueles formulados pelas ciências médicas). Submetidos a uma série de tratamentos e exames que, além de invasivos, eram ineficazes, bem como a um novo tipo de julgamento por parte de seus familiares, amigos e público leitor, Hervé Guibert e Caio Fernando Abreu elaboram nesses textos autobiográficos a experiência de um corpo que não mais lhes pertencia. Tomado ora pelas interferências médicas, ora pelas acusações sociais que, na época, eram ainda mais intensas, o corpo do sujeito soropositivo perde sua identidade ou passa a ter sua identidade moldada unicamente por terceiros. A escritura, em ambos os casos, aparece como um espaço de resgate do corpo, através de um processo de análise e elaboração estética de um corpo "perdido", que não pode mais existir senão dentro de outro corpo: o corpo do texto. 
ABREU, Caio Fernando. Pequenas Epifanias. Rio de Janeiro: Agir, 2006. . Os dragões não conhecem o paraíso. Rio de Janeiro: Nova Fronteira, 2010.

BARTHES, Roland. Aula. São Paulo: Cultrix, 2013.

BESSA, Marcelo Secron. Histórias Positivas. A literatura (des)construindo a AIDS. Rio de Janeiro: Record, 1997.

BLANCKEMAN, Bruno. Nouvelle et Autofiction : le cas Guibert. In: La nouvelle aux frontières des autres genres, du Moyen-Âge à nos jours. Bruxelles: Academia Bruylant, 2001. Disponível em http://www.herveguibert.net/\#!nouvelle-et-autofiction/c13vb. Acesso em 28 de Outubro de 2015.

BUTLER, Judith. Problemas de gênero: Feminismo e subversão da identidade. Rio de Janeiro: Civilização Brasileira, 2010.

CLASTRES, Pierre. A sociedade contra o Estado. São Paulo: Cosac \& Naify, 2012.

FOUCAULT, Michel. História da sexualidade I: a vontade de saber. Rio de Janeiro: Graal, 2010.

GAUSSEN, Frédéric. Foucault et Hervé Guibert, le compagnon d'agonie. In: Le Monde, 7 de maio de 2000. Disponível em http://lemegalodon.net/a3982-foucault-etherve-guibert-le-compagnon-d-ag.html. Acesso em 28 de Outubro de 2015.

GUIBERT, Hervé. À l'ami qui ne m'a pas sauvé la vie. Paris: Gallimard, 1990.

. La vie sida, entretien avec Antoine de Gaudemar. In: Libération. 1 de março de 1990. Disponível em http://www.liberation.fr/cahier-special/1998/03/19/lesauteurs-de-nos-25-ans-1990-guibert-la-maladie-de-l-amourherve-guibert-a-lesida-pour-qui-a-pris-_230790. Acesso em 28 de Outubro de 2015.

La mort propagande. Paris: Gallimard, 2009.

MAUSS, Marcel. As técnicas do corpo. In: Sociologia e Antropologia.

São Paulo: Cosac Naify, 2003.

SONTAG, Susan. Doença como metáfora, AIDS e suas metáforas. São Paulo: Companhia das Letras, 2007. 